\title{
Influence of teeth on the smile and physical attractiveness. A new internet based assessing method
}

\author{
Yoann Lopez $^{1,2}$, Jérémie Le Rouzic ${ }^{1,2}$, Valérie Bertaud ${ }^{1,2,3}$, Matthieu Pérard ${ }^{1,2,4}$, Justine Le Clerc ${ }^{1,2,4}$, \\ Jean-Marie Vulcain ${ }^{1,2^{*}}$ \\ ${ }^{1}$ Faculté d’Odontologie, Université de Rennes 1, Rennes, France \\ ${ }^{2} \mathrm{CHU}$ Rennes, Pôle d’Odontologie et Chirurgie Buccale, Rennes, France \\ ${ }^{3}$ EA 3888, IFR 140, Faculté de Médecine, Université de Rennes 1, Rennes, France \\ ${ }^{4}$ U6226, CNRS, Sciences Chimiques de Rennes, Equipe de Biomatériaux en Site Osseux, Rennes, France \\ Email: ${ }^{*}$ jean-marie.vulcain@univ-rennes1.fr
}

Received 19 January 2013; revised 24 February 2013; accepted 5 March 2013

\begin{abstract}
Objectives: Traditional methods for evaluating aesthetic perceptions of the teeth have involved panels of people observing photographs, and the person commenting on the appearance of the teeth generally is aware that his opinion of the dental appearance is being sought. The situation is artificial and may involve bias. We propose a novel method for evaluating the effect of dental imperfections on perceptions in which the participant is unaware of participating in a survey and in which his or her opinion is not sought. Rather, involvement in the study betrays the importance of dental aesthetics for the observer. Methods: Starting with a digitally manipulated photograph of a smiling young woman, two portrait photographs A and $B$ were produced in which the only differences were in the dentition revealed by the smile. The two photographs were anonymously posted on an online dating service site covering two large cities in southwestern France. During a period of one month, all "hits" on each of the photographs and all attempts to make contact were counted. Results: There was no significant difference between the number of hits on each of the portraits $A$ and $B$. On the other hand, the ratio of attempts to contact to hits showed a clear difference: the ratio was 4.8 times greater for Portrait $A$ than for Portrait B $(p<0.001)$. Conclusions: Digital manipulation of a photograph and internet dating sites provide an alternative to traditional questionnaires for evaluation of the contribution of dental factors to a person's physical attractiveness.
\end{abstract}

Keywords: Dental Aesthetics; Smile; Appearance; Communication; Internet

\footnotetext{
"Corresponding author.
}

\section{INTRODUCTION}

Physical appearance, especially that of the face, plays a key role in human communication. The mouth is a critical inter-relational crossroads, both physiologically and socially. In this context, teeth that are visible when smiling are important.

In 1972, Dion et al. [1] defined the physical attractiveness stereotype as "what is beautiful is good." Several years later, the meta-analyses of Eagly et al., Feingold, and Jackson et al. [2-4] of showed that people considered to be beautiful are perceived to be extroverted, popular, sociable and thus appeared more attractive and happier. This is why cosmetic surgery seeks to increase an individual's attractiveness [5].

The role of teeth in the perception of beauty has been widely accepted, including by the "American Academy of Cosmetic Dentistry", and as a result of a study conducted by Beall [5] in which only aesthetic dentistry achieved results close to cosmetic surgery. This raises the question of the ability of cosmetic dentistry to make the individual more attractive, since the study of Beall [5] showed clearly that the smile has a major impact on the physical attractiveness of the person. People considered beautiful are perceived as having desirable social qualities. The smile alone has a significant positive impact on the overall attractiveness and perception of personality.

Similarly, the appearance of the smile has a significant association with the initial success of an encounter. For Berry and Miller [6], physical appearance in general and especially the smile are more critical for men than for women. Trivers' parental investment model [7] had already defined the concept: women consider the skills necessary to progress in society to be more important than physical appearance.

In this context, cosmetic dentistry plays an undeniable role in one person's acceptance by another. A beautiful dental appearance is considered essential in certain oc- 
cupations, such as acting or modelling. Several studies in the United States conducted among former MBA students show that there is a very strong correlation between rank on a scale of beauty and professional income. For each additional unit on the scale of beauty, men earned $\$ 2600$ more per year and women \$2150 more than their counterparts [8].

Similarly, several studies cited above have shown that individuals who met the criteria for physical beauty were more relaxed and more sociable. Langlois et al. reported in a meta-analysis that a telephone survey had established a clear correlation between the perception of sociability of a group of respondents and judgments about the physical attractiveness of the same group [9].

This propensity toward physically beautiful people in is not seen just in adults, it is the continuation of a behaviour that appears early in childhood. It has been shown that children with normal dento-facial appearance were considered more beautiful, more desirable as friends and even more intelligent than those with Angle class III or class II occlusions, irrespective of sex [10].

This subject was also investigated by Fonte et al. [11], who evaluated the influence of dentofacial appearance on the interpersonal attractiveness of 802 Brazilian children aged 10 years. From an original face altered by computer to create three virtual faces, the first met normal aesthetic standards, the second had an Angle Class II occlusion and the third an Angle Class III occlusion. The first face was preferred by $68.9 \%$ of children.

Other studies by Mandall et al. and Al-Sarheed et al. [12,13], reported similar results. O’Brien et al. [14] even suggested that the motivation behind demand for orthodontic treatment in adolescents is associated more with the social implications of malocclusion rather than functional considerations.

Finally, Grzywacz [15] confirmed that adolescents attach great importance to cosmetic dentistry; he reported that $100 \%$ of a cohort of 84 young people aged 12 years considered the dental arch important in aesthetic facial appearance.

\section{AIMS OF THE STUDY}

In all the previously reported studies, the dental factor either was evaluated in the presence of other parameters or was confused with the smile; furthermore, most of the investigations were carried out by comparing the faces of different individuals. In a face, many parameters, such as eye colour, nose shape, the hair, the presence or absence of malformations, etc., as well as the smile and the teeth, contribute to the assessment of the individual.

But what is the real importance of the dental factor compared with other features? What is the impact of the teeth?

In this study, our goal was to test a new method of aes- thetic assessment using an Internet dating site, to evaluate the importance of physical attributes to a person's attractiveness. A secondary objective was to test this method by assessing the physical attractiveness of a face in which all parameters were constant except for the dental factor, thus measuring the influence of the teeth in the perception of an individual.

\section{MATERIAL AND METHODS}

Using as the starting point an image of a face of a Caucasian female of about thirty years of age, meeting the aesthetic criteria of Paris and Faucher [16], an anonymous digital portrait was created using image manipulation software (Gimp 2 ${ }^{\circledR}$; http://www.gimp.org/), then duplicated to obtain two identical images.

The first image, given the identification " $A$ ", was used without modification. In the second, identified as " $\mathrm{B}$," dental features were modified using the same software. While maintaining the same labial outline, a series of transformations was performed, applying fundamental criteria of cosmetic dentistry, as defined by Paris and Faucher [16], and those of Fradeani [17], concerning the aesthetics of the smile. The following changes were implemented:

- The right maxillary second premolar (tooth 15) and the left maxillary first premolar (tooth 24) were "repositioned";

- The right maxillary central incisor (tooth 21) was rendered slightly grey in colour;

- The left maxillary central incisor (tooth 11) was repositioned slightly labially;

- The neck of the right maxillary lateral incisor (tooth 22) was displaced in an incisal direction;

- The cuspal tips of the maxillary canines were accentuated.

The two portraits, A (Figure 1) and B (Figure 2) thus obtained could be superimposed as all their features, including the lips, were identical. Only their dental characteristics were different.

To assess the impact of the dental features on perceptions of the faces $\mathrm{A}$ and $\mathrm{B}$ in the most objective way possible and without investigator intervention, it was decided to place these two faces on an Internet dating site. The selected site is a leader in the field in France and advertises itself regularly on television channels. A fictitious background, identical for the two portraits except for residence, was created to give the two faces a personality as close as possible to character traits and interests prevalent in the general population and particularly in this type of profile (Figure 3).

So that the two portraits did not appear concomitantly, they were published in two different cities corresponding to the apparent places of residence. Two cities in southwest France, Bordeaux and Toulouse, were chosen. They 


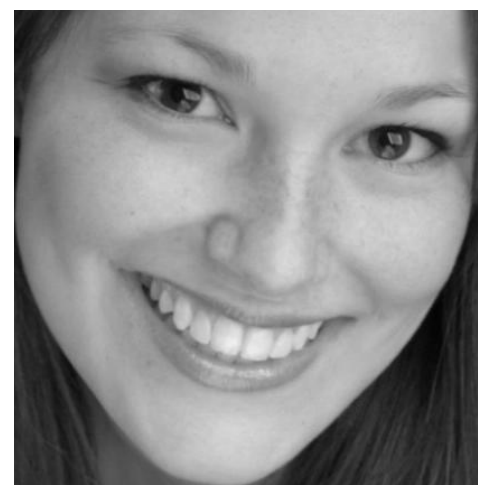

Figure 1. Portrait A.

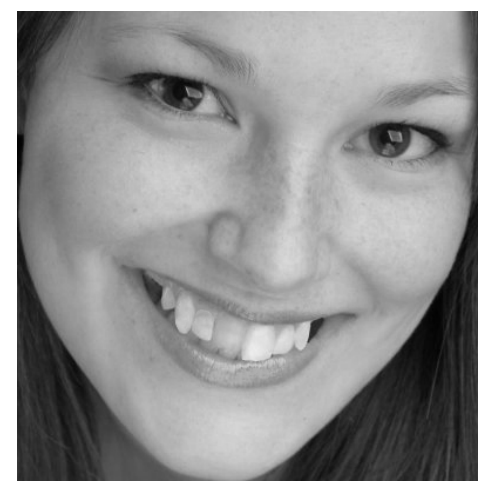

Figure 2. Portrait B (digitally modified).

\begin{tabular}{|c|c|}
\hline Listing details & Portraits A and B \\
\hline Date of birth & 05/01/1986 \\
\hline Place of residence & $\begin{array}{l}\text { Bordeaux, portrait B } \\
\text { Toulouse, portrait A }\end{array}$ \\
\hline Language spoken & French \\
\hline Intentions & Stable relationship \\
\hline Marital status & Single \\
\hline Profession & Nurse \\
\hline Height & $170 \mathrm{~cm}$ \\
\hline Figure & Slim \\
\hline Hair colour & Brown \\
\hline Eye colour & Chestnut \\
\hline Children & None \\
\hline Most marked characteristic & Shy, reserved \\
\hline Tobacco & Non-smoker \\
\hline Likes going out to... & $\begin{array}{l}\text { Restaurants, family, theatre, concerts, } \\
\text { cinema, evenings with friends, } \\
\text { other... }\end{array}$ \\
\hline Hobbies & $\begin{array}{l}\text { Shopping, art exhibitions/museums, } \\
\text { cooking, travelling, walking, animals, } \\
\text { art, others... }\end{array}$ \\
\hline Sporting activities & $\begin{array}{l}\text { Swimming, ski/snowboard, } \\
\text { horse riding, hiking/trekking, fitness. }\end{array}$ \\
\hline
\end{tabular}

Figure 3. Background of the profile. are similar in their demographic structure [18] and are culturally similar. Bordeaux has a population of about 240,000 and Toulouse of about 440,000 persons and each city is surrounded by a larger populated area. The city of Bordeaux was selected at random as the place of residence for picture B and Toulouse for picture A. Apart from the dental differences between the images, residence was the only variable that differed between the portraits. The two cities are about $240 \mathrm{~km}$ apart, so it was considered unlikely that the two portraits would appeal to the same persons.

Like other members of the site, each of the portraits A and $\mathrm{B}$ was allocated an e-mail address for receiving messages from other site members. When a person searches, a dozen profiles corresponding to the desired criteria are presented, with a thumbnail photograph too small to show the full details of the face. It is only when a visitor clicks a profile that it is displayed in full screen with high resolution, allowing a clear view of all the features of the face, including the smile and the teeth. Then the visitor can, if he wishes, contact the person by e-mail. The site remembers and tells the owner of the account the number of members who visited the profile and the number of members who sent an email.

Portraits A and B, with their background information, were left on the site for one month exactly (23 May 2011, 23:00 hours to 22 June 2011, 23:00 hours), at the end of which time the number of hits on the individuals and the number of e-mails received were noted. The outcome measure of interest was the proportion of hits that resulted in an e-mail. To avoid over-estimating the number of hits and e-mails, only the first hit and only the first contact was counted for each portrait, even when a person made several visits or sent several e-mails.

In a pilot test, it was found that any administrator connection to an account was included in the hit count and could lead to bias, by increasing the number of visits. To avoid this, only two connections were allowed, the first to open the account and insert the portrait on the site, the second to close the account. No further administrator intervention was undertaken during the period of the study.

The numbers of E-mails as a proportion of hits were compared using chi-square ( $1 \mathrm{df}, \alpha=5 \%$ ). This proportion is independent of the population sizes of the cities. The numbers of hits on each portrait was similarly tested $\left(\chi^{2} ; 1 \mathrm{df}, \alpha=5 \%\right)$.

The study protocol was reported to and approved by the CNIL (National Committee for Informatics and Freedom) (Declaration \#1562741 v 0).

\section{RESULTS}

Portrait A and Portrait B received respectively 425 and 461 visits during the month, an average of 13.7 daily hits 
to the portrait A and 14.8 to portrait $\mathrm{B}$. This difference was not statistically significant $\left(\chi^{2}=1.46 ; 1 \mathrm{df} ; \mathrm{p}>\right.$ $0.10)$.

During the same period, these visits were followed up by 71 e-mail contact requests to portrait A, a daily average of 2.29 e-mails; $16.7 \%$ of hits resulted in e-mails. For Portrait B, there were 16 contact e-mails, a daily average of 0.51 and just $3.47 \%$ of hits resulted in e-mails. The difference was statistically significant $\left(\chi^{2}=43.73 ; 1\right.$ df; $\mathrm{p}<0.001$; Figure 4).

Portrait A received statistically significantly more e-mails than did Portrait B.

\section{DISCUSSION}

The results indicate significantly and unambiguously that the dental factors play an important role in the physical perception of an individual and consequently in the establishment of a social relationship. The score of Portrait A, which corresponded with the aesthetic dentistry criteria defined by Paris and Faucher [16], is four times higher than the score obtained by Portrait B. The importance of aesthetic dental appearance would appear to be supported.

It should be recalled that this test was performed using a woman's face and it is likely that the vast majority of visitors were of the opposite sex. It would have been instructive simultaneously to use the same approach with a male portrait.

Digital manipulation seems well suited to this type of investigation; the digitisation of photographs allows all appearance features to be changed more and more precisely and a number of other studies have also used this method $[11,19]$. In this study, the dental characteristics were transformed significantly. Would more or less severe modifications have modulated the result? This question must be addressed in a wider study.

The internet dating site, which was used in an original way in this study, served as an independent tool, anonymous and reliable for quantifying data. It reduced the administrative effort required for the investigation and the time spent to acquire data. It was unaffected by any lack of objectivity in the investigator. In addition, it allowed full control of time, whether by the month exactly or by the hour precisely; it would allow decoys to be used to increase the accuracy of the results, and the investigation can be repeated as necessary. In this study we

\begin{tabular}{cccccc}
\hline Portrait & Hits & $\begin{array}{c}\text { Daily } \\
\text { mean hits }\end{array}$ & $\begin{array}{c}\text { e-mails } \\
\text { received }\end{array}$ & $\begin{array}{c}\text { Daily mean } \\
\text { e-mails }\end{array}$ & $\begin{array}{c}\text { e-mails/Hits } \\
\text { (\%) }\end{array}$ \\
\hline A & 425 & 13.7 & 71 & 2.29 & $16.70 \%$ \\
B & 461 & 14.8 & 16 & 0.51 & $3.47 \%$ \\
& NS & & & & $\mathrm{p}<0.001$ \\
\hline
\end{tabular}

Figure 4. Results. chose a very popular dating site but it could have been a professional recruitment site, although with a risk of more limited and more specific participation. The option of using two separate cities of residence, while creating an additional variable in the study, does not seem to have had any influence on the results. Indeed, the populations of these cities are similar, in terms of demographics, social culture and standard of living. This makes two relatively homogeneous source populations, which may explain why the number of hits received in each place of residence showed no significant difference.

Previous studies on this subject are qualified by possible biases resulting from the fact that the findings on dental criteria were obtained in the presence of other variables, and certainly on different faces. Often, respondents are directed to look especially at the teeth and their responses may be affected by this. This was not the case in the present study, where respondents' interests were social contact and they were unaware that they were participating in a study. Digital photography now makes it possible to manipulate the key elements of an image, such as the teeth, while maintaining everything else constant; this was a strong point of this investigation.

The choice of physical features and background characteristics of the two portraits, such as the profession of nurse (generally well regarded), was done in order to attract as many hits as possible. The main aim was to increase the power of our statistical tests. The number of hits, 425 for portrait A and 461 for Portrait B, seems to justify the choices made.

The scientific literature is in agreement that the smile and the teeth play a significant role in rendering a face attractive. They can convey an impression of social success and good health but subjectivity predominates in assessing their involvement, and outcome measures dependent on the cultural context [20]. On the other hand, the majority of studies focus on the smile $[5,16,17,19,20]$, yet the smile is multi-factorial. Van der Geld et al. [21] have identified and quantified the elements that make the smile attractive: the size of the teeth, lip position and the extent of gingival display.

The study of De Deus et al. [19] is the closest to the one we present. Indeed, from one face, the authors developed a series of five digitally manipulated images of a smile, each with a different dental criterion, such as a smile combined with midline displacement or a smile combined with a diastema. A hierarchy of smiles was then formally established by a group of ten women and ten men.

The present study, the results of which are generally in accordance with the literature, has several merits: firstly, only the dental parameters vary while all the other factors involved in the attractiveness of a personare maintained constant; secondly, it invites evaluation of the 
modification by persons who do not know they are participating in a test, an original method; and, finally, it attracts a sufficiently large number of opinions to permit statistically reliable conclusions.

The result of this study shows clearly that the teeth affect the perception of a person. This result therefore underlines the potential of cosmetic dentistry. It would be interesting to conduct a similar study by restoring the maxillary premolars, then studying dental discolouration and so on, so that the impact of dental disorders could be prioritised. This study is preliminary one; two other investigations of the societal impact of dental appearance in the workplace are planned.

Today, the self-image is manipulated to optimise physical appearance. Aesthetics now occupies a prominent place in which dental care is justified. In addition to the concept of health, factors such as social position, seduction, beauty, youth and well-being must be considered; Tirlet [22] considers these the main reasons for most dental consultations and, with the increase in longevity, demand will grow!

\section{CONCLUSION}

WHO defines health as "a state of complete physical, mental and social well-being;" the teeth contribute to this balance. For centuries, portraits did not reveal the teeth. Today, the world in which we live, with its focus on communication and image, makes the teeth a very important appearance factor. The results of this study would suggest that having an ideal dentition can make it 4.8 times more likely that others will desire to enter into a relationship with such a female person. Hitherto studies have used volunteer panels to evaluate factors influencing physical attractiveness; this new methodology, using Internet dating sites, represents a real innovation since it allows the opinions of observers unaware of the purposes of a study to be collected.

\section{REFERENCES}

[1] Dion, K.K., Berscheld, E. and Walster, E. (1972) What is beautiful is good. Journal of Personality and Social Psychology, 24, 285-290. doi:10.1037/h0033731

[2] Eagly, A.H., Ashmore, R.D., Makhijani, M.G. and Longo, L.C. (1991) What is beautiful is good, but...: A metaanalytic review of the research on the physical attractiveness stereotype. Psychological Bulletin, 110, 109-128.

[3] Feingold, A. (1992) Good looking people are not what we think. Psychological Bulletin, 111, 304-341. doi:10.1037/0033-2909.111.2.304

[4] Jackson, L.A., Hunter, J.E. and Hodge, C.N. (1995) Physical attractiveness and intellectual competence: A meta-analytic review. Social psychology quarterly, 58, 108-122. doi:10.2307/2787149
[5] Beall, A.E. (2007) Can a new smile make you look more intelligent and successful? Dental Clinics of North America, 51, 289-297. doi:10.1016/j.cden.2007.02.002

[6] Berry, D.S. and Miller, K.M. (2001) When boy meets girl: Attractiveness and the five-factor model in opposite-sex interactions. Journal of Research in Personality, 35, 6277. doi:10.1006/jrpe.2000.2304

[7] Trivers, R. (1985) Social evolution. Benjamin/Cummings, Menlo Park.

[8] Frieze, I.H., Olson, J.E. and Russell, J. (1991) Attractiveness and income for men and women in management. Journal of Applied Social Psychology, 21, 1039-1057. doi:10.1111/j.1559-1816.1991.tb00458.x

[9] Langlois, J.H., Kalakanis, L., Rubenstein, A.J., Larson, A., Hallam, M. and Smoot, M. (2000) Maxims or myths of beauty? A meta-analytic and theoretical review. Psychological Bulletin, 126, 390-423. doi:10.1037/0033-2909.126.3.390

[10] Shaw, W.C. (1981) The influence of children's dentofacial appearance on their social attractiveness as judged by peers and lay adults. American Journal of Orthodontics, 79, 399-415. doi:10.1016/0002-9416(81)90382-1

[11] Fonte, P.P., Colares, V., Santos, F. and Caraciolo, G. (2008) The social impact of children's dentofacial appearance. European Archives of Paediatric Dentistry, 9, 84-89. doi:10.1007/BF03262615

[12] Mandall, N.A., McCord, J.F., Blinkhorn, A.S., Worthington, H.V. and O’Brien, K.D. (1999) Perceived aesthetic impact of malocclusion and oral self-perceptions in 14- to 15-year-old Asian and Caucasian children in greater Manchester. European Journal of Orthodontics, 21, 175-183.

[13] Al-Sarheed, M., Bedi, R. and Hunt, N.P. (2003) Orthodontic treatment need and self-perception of 11 - 16-yearold Saudi Arabian children with a sensory impairment attending special schools. Journal of Orthodontics, 30, 3944. doi:10.1093/ortho/30.1.39

[14] O’Brien, C., Benson, P.E. and Marshman, Z. (2007) Evaluation of a quality of life measure for children with malocclusion. Journal of Orthodontics, 34, 185-193.

[15] Grzywacz, I. (2003) The value of the aesthetic component of the index of orthodontic treatment need in the assessment of subjective orthodontic treatment need. European Journal of Orthodontics, 25, 57-63. doi:10.1093/ejo/25.1.57

[16] Paris, J.C. and Faucher, A.J. (2003) Le guide esthétique. Comment réussir le sourire de vos patients. [Guide to aesthetics. How to succeed with your patient's smile]. Quintessence International Publishing, Paris.

[17] Fradeani, M. (2006) Réhabilitation esthétique en prothèse fixée. Tome 1: Analyse esthétique. [Aesthetic rehabilitation with fixed prostheses. Volume 1. Aesthetic analysis]. Quintessence International Publishing, Paris.

[18] Kocoglu, D., Martial, F., Roosz, P. and Tronyo, J. (2011) Tableaux de l'économie Française [Tables of the French economy]. INSEE, Edition 2011, 17. http://insee.fr/fr/ffc/tef/tef2011/tef2011.pdf. Last accessed $\underline{11 / 06 / 2011}$ 
[19] De Deus Tupinamba Rodrigues, C., Magnani, R., Salete Candido Machado, M. and Oliveira, O.B. (2009) The perception of smile attractiveness. Angle Orthodontist, 79, 634-639. doi:10.2319/030508-131.1

[20] Nathus, S.A. and Nevid, J.S. (2003) Physical attractiveness in Psychology and the challenges of life adjustment in the new millennium. John Wiley \& Sons, New York.
[21] Van der Geld, P., Ooterveld, P., Van Heck, G. and Kuijpers-Jagtman, A.M. (2007) Smile attractiveness. Angle Orthodontist, 77, 759-765. doi:10.2319/082606-349

[22] Tirlet, G. (2004) La demande esthétique actuelle en odontologie. [Current demand for aesthetics in dentistry]. Information Dentaire, 86, 1943-1948. 